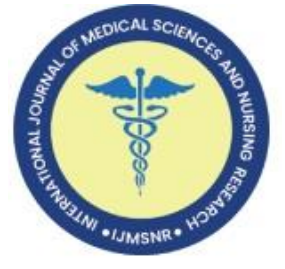

\title{
Availability, Utilization of Iodized Salt, Status of Iodine Deficiency Disorder and Level of Iodine Content at Households' Salt among Coastal Areas of Population in India
}

\author{
Senthilvel Vasudevan ${ }^{1}$ (D), Murugan Natesan²
}

${ }^{1}$ Assistant Professor of Statistics, Department of Pharmacy Practice, College of Pharmacy, King Saud Bin Abdulaziz University for Health Sciences, Riyadh, Saudi Arabia. ${ }^{2}$ Professor, Department of Community Medicine, Pondicherry Institute of Medical Sciences, Kalapet, Pondicherry, India.

\begin{abstract}
Background: Iodine deficiency disorder is common public health problem in developed and developing countries. In Worldwide, nearly $70 \%$ of the households only using adequate iodized salt in their regular food. To estimate the household salt utilization, prevalence of goiter, status of iodine deficiency disorder, and to find the iodine level at household level in the study areas.

Materials and Methods: We have done a community-based observational study on IDD in the coastal areas of Villupuram District, Tamil Nadu with examined households salt in 1233 households in selected eight villages. All data were analyzed using Chi-Square test. pvalue $<0.05$ was considered as statistically significant.

Results: Totally 1233 households were recruited and incorporated in this study. Among 1233 households, male 385 (31.2\%) and female $848(68.8 \%)$. The male and female age-group was showed statistically highly significant association with p $<0.01$. Out of 1233 individuals, $141(11.4 \%)$ were found as total goiter. The prevalence of goiter was $105(12.4 \%)$ in female than male was $36(9.4 \%)$ and no statistical association between gender among goiter prevalence $(\mathrm{p}>0.05)$.

Conclusion: From our present study findings, we have concluded that majority of the study population was used iodized salt in their regular food. But, very less adequately iodized salts were available nearby study areas. Nevertheless, majority of the households didn't know about the benefits about the usage of iodized salt. Health education is needed in to the shopkeepers and local vendors. This will be conducted by non-Governmental organization, Government organization and other nearby medical colleges.
\end{abstract}

Keywords: household salt, utilization, iodine, iodine deficiency disorder, coastal areas

Article Summary: Submitted: 02-October-2021 Revised: 20-November-2021 Accepted: 10-December-2021 Published: 31-December-2021

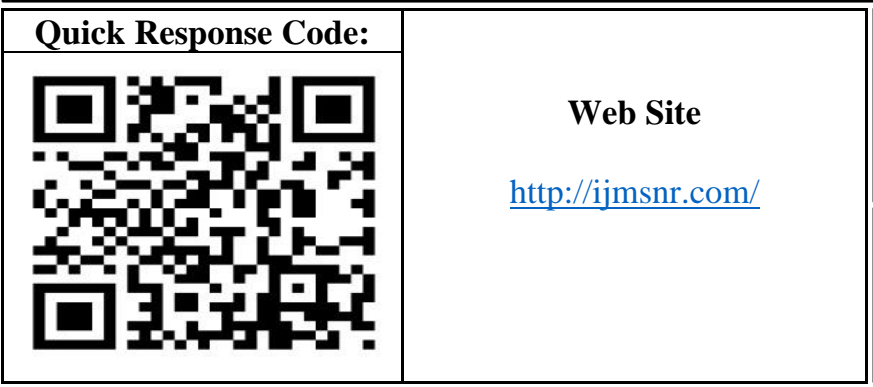

This is an open access journal, and articles are distributed under the terms of the Creative Commons Attribution-Non-Commercial-ShareAlike 4.0 International License, which allows others to remix, tweak, and build upon the work non-commercially, as long as appropriate credit is given and the new creations are licensed under the identical terms.

\section{Introduction}

Iodine is a very important vital micronutrient in human food in their routine life and it needs to produce thyroid hormones. It is needed in all stages of life. [1] In Worldwide, nearly $70 \%$ of households only use adequate iodized salt in their daily food. [2, 3] Changes needed immediately in the iodized salt coverage among countries. [4] India is the first nation to initiate salt with iodized salt but there are some big problems in implementing it through the National programme. So, ensuring the availability of iodized salt, utilization through monitoring systems. [5] In another one review on the National coalition for sustained optimal iodine intake by Yadav et al [6] has reported India could achieve universal salt iodization by 2015 .

Iodine deficiency in a household's salt is affecting a child's growth, intelligence quotient (IQ) level and in many ways. [7] The consumption of iodine per day for up to 6 months, infants up to 1 years, up to 8 years, up to 13 years, up to 18 years and adults is $110,130 \mathrm{mcg}, 90 \mathrm{mcg}$, $120 \mathrm{mcg}, 150 \mathrm{mcg}$ and $150 \mathrm{mcg}$ respectively. [8] Iodized salt coverage was very low in Tamil Nadu. [9] If the pregnant women don't consume the adequate level of iodine $250 \mathrm{~g} / \mathrm{per}$ day [10] in their food as per WHO recommendation, then the fetal growth, child initial years' growth, child's brain development would be affected severely. Iodine is an important micro nutrient in food to the human brain development and reduce the abnormalities in the pregnant women, child bearing, enough children brain and IQ development. [25] We contacted this study to find the iodine content of household salt, its availability and its effect in the study areas of Tamil Nadu. Our study is the first study in this study area. Main objectives of the present study were to estimate the household salt utilization and availability of iodized salt, status of Iodine

How to cite this article: Vasudevan S, Natesan M. Availability, Utilization of Iodized Salt, Status of Iodine Deficiency Disorder and Level of Iodine Content at Households' Salt among Coastal Areas of Population in India. Int J Med Sci and Nurs Res 2021;1(2):29-37 
Deficiency Disorder and among gender, and level of iodine content at households' salt among coastal areas of population in Villupuram District, Tamil Nadu, India.

\section{Materials and Methods:}

Study design, area and period of conducted this study: We have done a community-based, cross sectional study in the area of Anaichikuppam, Pondicherry Institute of Medical Science Rural Health Centre, Marakkanam block of Villupuram district, Tamil Nadu. The data was collected in the one-month period of February 2012.

Allocation of households among study areas: We have collected information from 1233 households by using convenient sampling method and included in our present study. In this present study, we have randomly selected and included 8 villages out of 16 villages namely, Kil Pudhupattu, Koonimedu, Chettikuppam, Anumandai, Kil Pettai, Parichamedu, Alapakkam, and Orani as shown in Figure-1.

Selection of study participants: We have recruited and included all individuals those were living in the Pondicherry Institute of Medical
Sciences, Rural Health Center, Anaichikuppam in Marakkanam. Development Block of Villupuram district, Tamil Nadu, India.

Inclusion Criteria: In our study, we have incorporated all residents living in eight villages with one year and above aged $\geq 3$ years. Because, what type of difficulties or effects would happen to the children with aged 3 or more. To be found by this study.

Exclusion Criteria: Children with aged $<3$ years and those who were affected by chronic diseases and severe communicable diseases.

Estimation of sample size for the study: As per existing literature by Roy et. al. [11] in his study he has found/explicated that the households with adequately iodized salt of $>15$ ppm was $62.4 \%$, statistical power $80 \%$, allowable error $5 \%$ and level of significant $95 \%$, the required sample size with formula, required minimum sample size $(\mathrm{N})=4 \mathrm{pq} / \mathrm{d}^{2}=965$ households. But we have included 1233 households in our study. One responsible person from each household was interviewed and recorded the usage of iodized salt in their respective households. 1233 individuals available at the time of face-to-face survey in these households were examined for goiter.

\section{Figure-1 Distribution of villages in the study area}

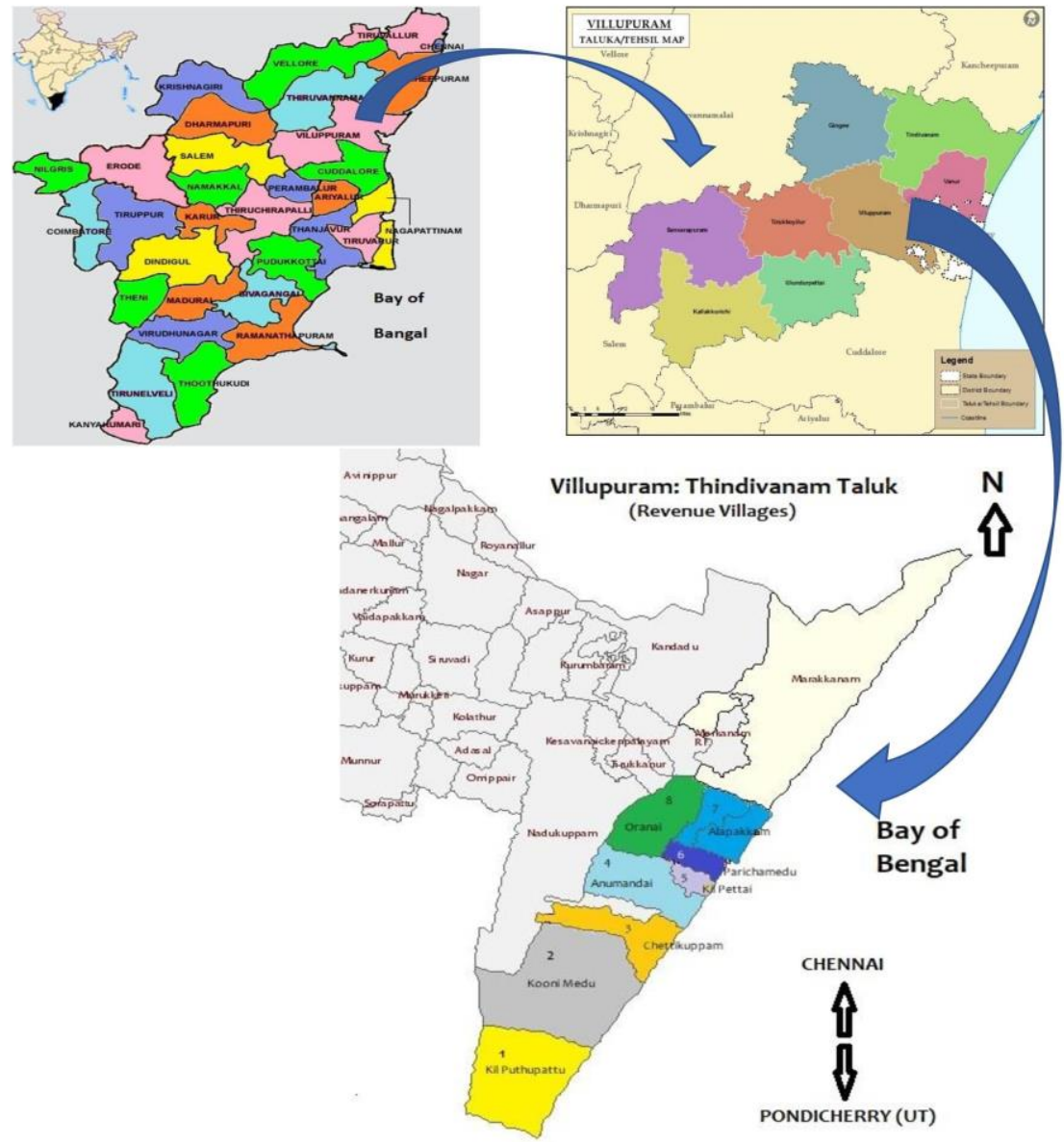


About the questionnaire: The questionnaire was framed by the faculties of the department and it had three parts. Part-A: Basic and Socio-demographic characteristics: name of village, household number, name of the family members, age, gender, religion, educational level, source of drinking water and the income of the family. Part-B: Grading of Goiter: The goiter grading of all the individuals available in the household was recorded. The questionnaire was tested properly and discussed through presented that in front of the Department faculties and in the institutional research committee members and corrected according to the comments. The examination was done respondents stood in front of the examiner, who looked carefully at the neck for any sign of visible thyroid enlargement.

\section{Grading of Goiter was graded according to the WHO classification} as follows:

Classification of Goiter grading of palpation [12] Grade: 0 No palpable or visible goiter; Grade-1: A goiter that is palpable but not visible when the neck is in the normal position; and Grade-2: A swelling in the neck that is clearly visible when the neck is in a normal position and is consistent with an enlarged thyroid when the neck is palpated a thyroid gland will be considered goitrous when each lateral lobe has a volume greater than the terminal phalanx of the thumbs of the subject being examined. Part-C: Iodine level of salt at household level: The household salts were tested for qualitatively on spot with MBI kit provided by Government of India and United Nations Children's Fund (UNICEF) [13, 14, and 15]. The iodine concentration was recorded as $0,7,15,30 \mathrm{ppm}$.

Selection of participants: In the present study, we have approached 1356 households in the 8 selected villages, 1233 households were recruited by face-to-face interviewed with pre-designed and pre-tested questionnaire in the local language TAMIL. Totally, 25 under graduate medical students those who were in the seventh semester were trained for two weeks by teaching staffs of Department of Community Medicine. Data were collected by trained students under the supervision of the Department of Community Medicine faculties, post graduate medical students, and with the help of interns and social workers of the RHC of PIMS. Study participants were the residents of the households those who were available using simple random sampling method at the time of survey. The response rate was $90.9 \%$.

Method of data collection: A house to house survey in the selected villages was done in one-month period. The purpose of the study was elaborately explained to the study participants. The consenting individuals were included in the study. The proper permission was obtained from the respective village administration officers and authorities before conducting our study. Data were collected only from the head of the family of each house at the time of data collection by using a structured questionnaire. Socio-economic status was determined using the Modified B G Prasad classification of socio-economic status 2013. The revised Prasad's Classifications based on 2013 was Social Class-I: 5113 and above; Social Class-II: 2557 - 5112; Social ClassIII: 1533 - 2556; Social Class-IV: 767 - 1532; and Class-V: less than 767. [16] Iodine level of salt: [17] By rapid kit testing, the level of Iodine $\geq 15 \mathrm{ppm}$ then it is called adequately iodized salt and the level of Iodine $<15 \mathrm{ppm}$ then it is inadequately iodized Salt.
The level of iodine is adequate in the food salt then only all free from some diseases like thyroid enlargement and goiter.

Data Management and Statistical Analysis Used: The data were organized, compiled and formulated by Microsoft Excel 2010 [Office 360, Microsoft Ltd., USA] and were analyzed by using statistical software SPSS 21.0 Version [IBM SPSS Ltd., USA]. The continuous variables were expressed using descriptive statistics like mean, and standard deviation and categorical variables were expressed using frequency and proportions. To find the association between gender and goiter by using bi-variate analysis chi-square test. $\mathrm{p}<0.05$ was fixed as level of significant.

Ethical consideration: Ethical approval was taken from the Institutional Ethics Committee of Pondicherry Institute of Medical Sciences, Pondicherry before conducting our study. Proper permission was obtained from the village administrative officer and village head to conduct our study. We have received written consent form each in-charge of the household in the study areas. We have explained in the local language TAMIL about the purpose of the study, its importance, potential risks and benefits of participating, procedure of maintaining confidentiality to all the study participants in this study. We didn't get any type of financial from the parent institution or from any type of financial institution and we didn't give any incentives to the study participants. Anonymity and confidentiality were ensured throughout the study

\section{Results:}

In this present study, we have visited and planned to conduct the study of totally 1356 households at the time of study period in the selected 8 villages. But, totally 1233 households were selected from 8 villages. Out of 1233 households, $135(10.95 \%)$ households were from Kil Pudhupattu, 422 (34.23\%) Koonimedu, 86 (6.97\%) Chettikuppam, 233 (18.89\%) Anumandai, 156 (12.65\%) Kil Pettai, 118 (9.57\%) Parichamedu, $37(3.00 \%)$ Alapakkam, and 46 (3.74\%) households from Orani were interviewed by house-to-house survey were randomly selected and included in our present study as shown in Figure - 1. In that, 95 houses were locked due to unavailability of individuals and 28 household's in-charge refused to participate in our study. So, finally we have selected and incorporated 1233 households in our study. Hence, the non-response rate of our study was $2.2 \%$. After this elimination of these, we have selected and included 1233 households in our main study. From these households we have interviewed 1233 individuals as shown Figure-2.

Basic socio-demographic variables of the study population: Totally 1233 households were recruited and incorporated in this study. Out of 1233 households, each one house, one responsible person (head of the house) was selected and collected the data through questionnaire. Among 1233 households, male 385 (31.2\%) and female $848(68.8 \%)$. In our present study, sex-ratio was 1:2.2. Most of the respondents were female gender and study participants were lying in the age-group in between 21-50 years and very few $20(1.6 \%)$ in the age-group of 61 and above. The association between age-groups and gender was shown statistically highly significant with $\mathrm{p}$-value $=$ $0.006(\mathrm{p}<0.01)$. 
In 1233 surveyed households, 975 (79.1\%) were Hindus, $230(18.7 \%)$ were Muslims, and $28(2.3 \%)$ Christian. The water sources of the households bore well, piped water (provided by metro water supply of Tamilnadu), hand pump and mineral water. The major sources of drinking water were well $567(46.0 \%)$. According to socio-economic status, more than half of the households were under the middle class and more than $1 / 4^{\text {th }}$ of households was under the lower middle class. Very few of the households were under the upper-class group as per the Modified BG Prasad Classification 2013.

Status of iodine deficiency disorder level among households: Among 1233 individuals were spot examined by MBI kit for iodine deficiency disorder. Total goiter (Grades $1 \& 2$ combined) prevalence (TGP) was $141(11.4 \%)$. The prevalence of goiter was $12.4 \%$ in females than male was $9.4 \%$. But there was no statistical association between gender among goiter prevalence Chi-Square value $=1.137$ with $\mathrm{p}$-value $=0.980(>0.05)$ as shown in Table $-\mathbf{1}$.

Utilization of iodized salt in the study areas among households: In 1233 households, majority 874 (70.9\%) households hadn't known about the benefits about the usage of iodized salt in their regular food and $359(29.1 \%)$ households responded to the perceived benefits of using iodized salt. $238(19.3 \%)$ of the households that used iodized salt was good for their health. $28(2.3 \%)$ respondents felt that the iodized salt is clean as compared to non-iodized salt. It was interesting to note that $15(1.2 \%)$ respondents were aware of the importance of iodized salt in brain development in children, and physical growth of children. Another $12(1.0 \%)$ were answered its use is good during pregnancy in women. $8(0.6 \%)$ were to prevent illness, $6(0.5 \%)$ were it added taste to their food,

Table: 1 Distribution of age-groups among gender for goiter examination ( $N=1233)$

\begin{tabular}{|c|c|c|c|c|c|c|c|}
\hline \multirow{3}{*}{$\begin{array}{l}\text { Age }- \text { Groups } \\
\text { (in years) }\end{array}$} & \multicolumn{4}{|c|}{ Gender } & \multirow{3}{*}{$\begin{array}{c}\text { Chi- } \\
\text { Square } \\
\text { test value } \\
\& \\
\text { p - value }\end{array}$} & \multirow{3}{*}{$\begin{array}{c}\text { Total } \\
\text { N (\%) } \\
1233 \\
(100 \%) \\
(1)+(3)\end{array}$} & \multirow{3}{*}{$\begin{array}{c}\text { Total Goiter Rate } \\
\text { N (\%) } \\
141(11.4) \\
(2)+(4)\end{array}$} \\
\hline & \multicolumn{2}{|c|}{$\begin{array}{c}\text { Male } \\
\mathbf{3 8 5}(\mathbf{3 1 . 2 \% )}\end{array}$} & \multicolumn{2}{|c|}{$\begin{array}{c}\text { Female } \\
848(68.8 \%)\end{array}$} & & & \\
\hline & $\begin{array}{l}\mathrm{n}(\%) \\
(\mathbf{1})\end{array}$ & $\begin{array}{c}\text { Goiter } \\
36(9.4 \%) \\
\text { (2) }\end{array}$ & $\begin{array}{c}\text { n (\%) } \\
(3)\end{array}$ & $\begin{array}{c}\text { Goiter } \\
105(12.4 \%) \\
(4)\end{array}$ & & & \\
\hline$\leq 10$ & $10(15.4)$ & $1(14.3)$ & 55 (84.6) & $6(85.7)$ & \multirow{7}{*}{$\begin{array}{c}18.087 \\
0.006 \\
p<0.01\end{array}$} & $65(5.3)$ & $7(5.0)$ \\
\hline $11-20$ & $36(33.0)$ & $4(25.0)$ & $73(67.0)$ & $12(75.0)$ & & $109(8.8)$ & $16(11.3)$ \\
\hline $21-30$ & $110(31.8)$ & $8(20.0)$ & $236(68.2)$ & $32(80.0)$ & & $346(28.1)$ & $40(28.4)$ \\
\hline $31-40$ & $134(37.0)$ & $11(29.7)$ & $228(63.0)$ & $26(70.3)$ & & $362(29.4)$ & $37(26.2)$ \\
\hline $41-50$ & $55(25.6)$ & $7(28.0)$ & $160(74.4)$ & $18(72.0)$ & & $215(17.4)$ & 25 (17.7) \\
\hline $51-60$ & $32(27.6)$ & $5(33.3)$ & $84(72.4)$ & $10(66.7)$ & & $116(9.4)$ & 15 (10.6) \\
\hline 61 and above & $8(40.0)$ & $0(0)$ & $12(60.0)$ & $1(100.0)$ & & $20(1.6)$ & $1(0.7)$ \\
\hline
\end{tabular}


Figure: 2 Flowchart of the process of allocation of villages and households in the study area $(\mathrm{N}=1233)$

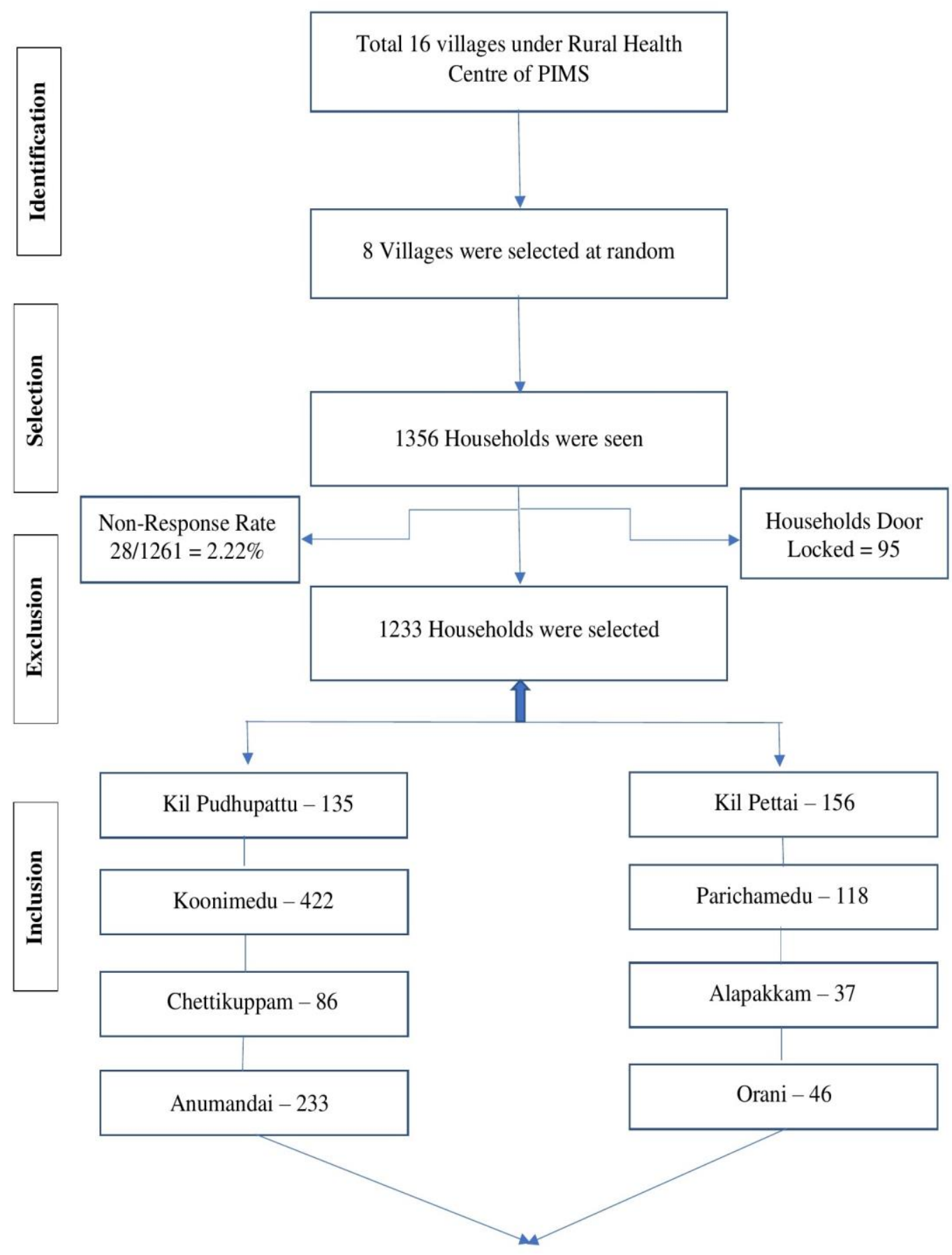


$1(0.1 \%)$ were prevented anomaly, $1(0.1 \%)$ were answered iodized salt was useful to their children's health, and 44 (3.6\%) weren't aware about anything of iodized salt and its benefits. In our study, the overall adequately iodized $(\geq 15 \mathrm{ppm})$ salt utilized by the households was $26.0 \%$ [(320/1233)*100]. Most $960(77.9 \%)$ of the respondents did not know if there was any disadvantage in using iodized salt, 244 (19.8\%) of the 1233 respondents felt that use of iodized salt was of no disadvantage. $18(1.5 \%)$ respondents felt that there was some disadvantage in using iodized salt. The disadvantages as said by the households that $10(0.8 \%)$ were high cost, followed by hypertension $3(0.2 \%), 1(0.1 \%)$ diabetes mellitus, $1(0.1 \%)$ kidney disease, and 2 $(0.2 \%)$ were told the iodized salt caused obesity.

\section{Availability of types of salts in the study areas:}

Among 1233 households, 540 (43.8\%) households were purchased powered salt and in that $159(29.4 \%)$ households were identified as adequate (15ppm and above) iodine salt and $693(56.2 \%)$ were purchased crystalline salt and in that $161(23.2 \%)$ were identified as adequate (15ppm and above) iodine salt as shown in Table $\mathbf{- 2}$.

Place of buying salts and types of salts among households:

Total 1233 households, $540(43.8 \%)$ were bought powered salt and the remaining $693(56.2 \%)$ were bought crystalline salt. Hence, more than half of the study population bought crystalline salt. Out of 1233 households, $858(69.6 \%)$ purchased salt in local grocery stores. In that, $396(45.2 \%)$ were purchased powered salt and in that, $90(22.7 \%)$ were identified as adequate iodine (15ppm and above) salt. Among 858 households, $462(54.8 \%)$ purchased crystalline salt and in that, 30 $(6.5 \%)$ were identified as adequate iodine (15ppm and above) salt.

Out of 1233 households, $86(7.0 \%)$ purchased salt in nearby village markets. In that, $71(82.6 \%)$ were purchased powered salt and in that, $180(25.4 \%)$ were identified as adequate iodine (15ppm and above) salt. Among 86 households, 15 (17.4\%) were purchased crystalline salt and in that, $2(13.3 \%)$ were identified as adequate iodine (15ppm and above) salt. Out of 1233 households, $160(13.0 \%)$ were purchased

Table: 2 Distribution of place of buying salts and types of salts among households $(\mathrm{N}=1233)$

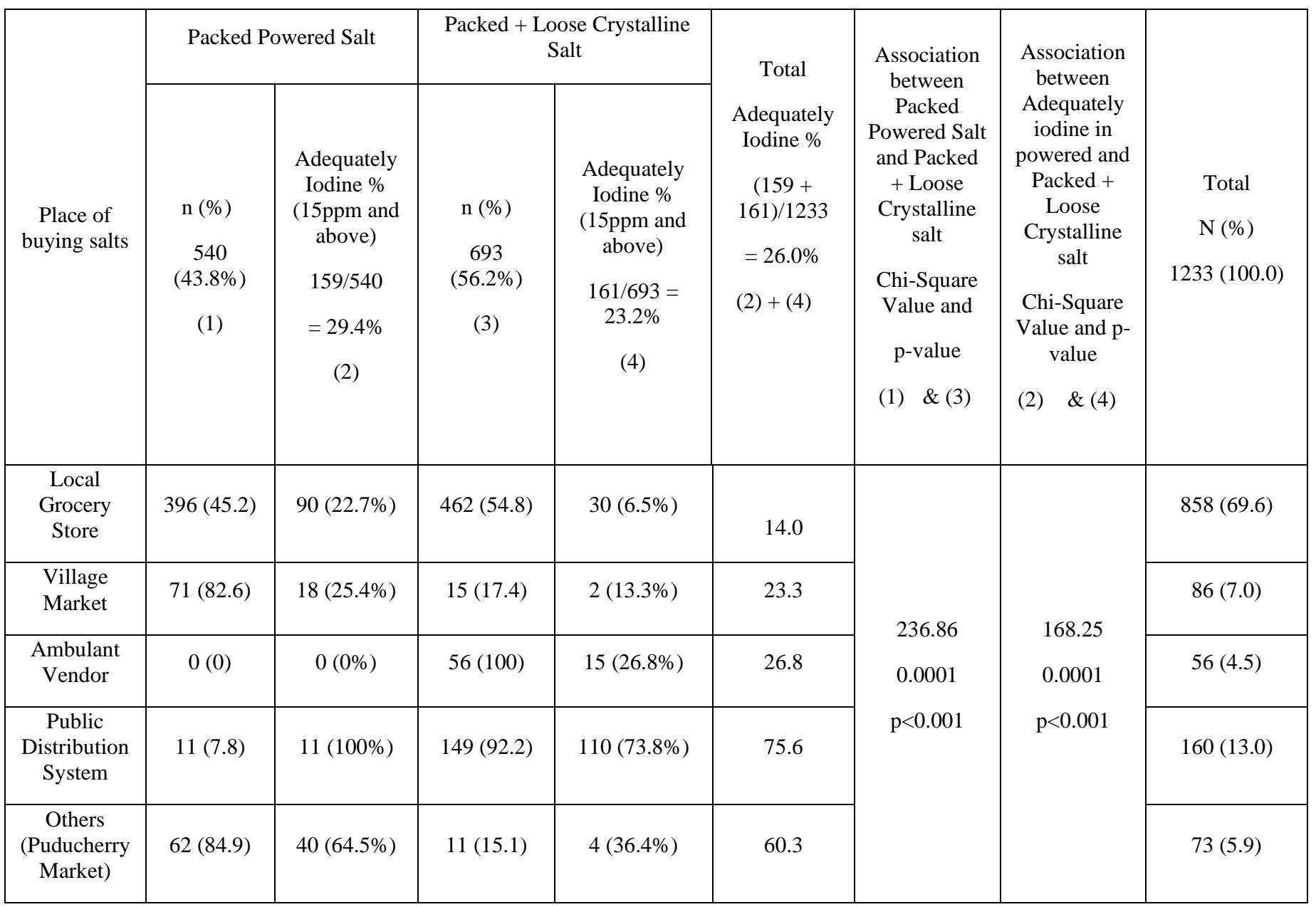


salt through the public distribution system. In that, $11(7.8 \%)$ were purchased powered salt and in that, $11(100.0 \%)$ were identified as adequate iodine (15ppm and above) salt. Among 160 households, 149 $(92.2 \%)$ were purchased crystalline salt and in that, $110(73.8 \%)$ were identified as adequate iodine (15ppm and above) salt. The households' members purchased salt from ambulant vendors and in other (Puducherry Market) places. Association between Packed Powered Salt and combined packed, loose Crystalline salt was showed a significant association with Chi-Square Value $=236.86$ and $\mathrm{p}$-value $=0.0001 \quad(<0.001)$ and Association between Adequately iodine in powered and combined packed, loose crystalline salt Chi-Square Value $=168.25$ and $p$-value $=0.0001$ were listed in the Table2. Hence, out of 1233 households 320 (26.0\%) were used iodized salt in their regular food.

Maintenance of salt containers, type of storage of salt, and places of storage in the households: Majority 1176 (95.4\%) of the households used containers with a lid for storing the salt. Whereas, 18 $(1.5 \%)$ used containers without lid and another $27(2.2 \%)$ households did not transfer the salt to any container, but stored it in its original packet itself and others $12(1.0 \%)$. ie., others meant 8 households were stored the salt in gunny bags and another 4 in paper to wrap the salt. Majority $1080(87.6 \%)$ of the households were stored salt inside the cabinets in their respective kitchen, another 47 (3.8\%) stored on top of the table, $76(6.2 \%)$ households were stored above the stove, and $30(2.4 \%)$ were on the floor in the kitchen. Out of 1233 households, $76(6.2 \%)$ households knew that they weren't using iodized salt. Only $551(44.7 \%)$ of the respondents knew that they were using iodized salt. A significant 601 (48.7\%) number of households weren't aware of whether the salt used in their houses was iodized. Among 1233 households, 106 (8.6\%) households responded for "what reasons they didn't use the iodized salt in their food?". 60 (4.9\%) of the households responded the reason was rate of the iodized salt was more in cost wise; $34(2.8 \%)$ were traditionally buying crystalline salt from the ambulant vendor, and $12(1.0 \%)$ were responded as not available in the local areas. ie., households' members responded that it is very difficult to buy iodized salt because grocery shops are far away from their residing place.

\section{Discussion:}

IDD problems have become a public health problem on a World level. [18] These IDD problems are present throughout the country India. In our present study, female gender was more than male gender. Similar type of results was revealed by Tariku and Mazengia conducted in Northwest Ethiopia. [19] In this study, total goiter prevalence (TGP) was $11.4 \%$. In the year $1992-2002$ the TGP was estimated in the rage of $17.6-18.2 \%$ by World Health Organization (WHO). [20] In our study, $26 \%$ of a household's salt contained adequate iodine content. Whereas, a study by Kapil in the year 2001 had mentioned high, ie, adequate salt ( $\geq 15 \mathrm{ppm}$ ) was used in $35 \%$ of households in Kanchipuram district. [21] Moreover, in another one study by Deepika et. al. had shown very high adequate iodine content in $3 / 4^{\text {th }}$ of households' salt in Prakasam district, Andhra Pradesh. [22] In our study, more than $1 / 3^{\text {rd }}$ of households responded to the perceived benefits of using iodized salt. But, a report of eight states in India showed a high $45.1 \%$ of households avail of iodized salt by awareness of iodized salt than our present study. [23]

The availability and utilization of adequately iodized salt was mentioned as very low by Taiiku and Mazengia. [19] IDD is a major problem in 130 countries. So, regular survey relates to the magnitude of IDD, iodine and its benefits related information, education and communication (IEC) programs conducted and construct a related monitoring agency is needed to improve or ensure the iodized salt to distribute to the affected communities/areas. [24] Iodine content is low in the diet salt will cause many problems like hypothyroidism, damage in brain development, mental effects, deaf and dump, psychological problems, abortion, deficit in fetal growth and also fetal death in pregnancy period in women. Due to IDD many problems have happened in pregnancy and in the child births in India. This will be eradicated by fortified salt with iodine or double fortified salt with iodine and iron. [25] In our present study, adequately iodized salt (AIS) utilized by the households of the study areas was $26.0 \%$. But, a study in Northwest Ethiopia by Tariku and Mazengia have revealed that the utilization of very high adequate iodized salt was 63.3\%. [19] Whereas, in another one study by Pandav et al. [26] has mentioned $71 \%$ households consumed AIS ( $\geq 15 \mathrm{ppm}$ ) as their diet salt. In another one study in Bihar by Sankar et al. [27] have mentioned that $40.1 \%$ household salt was found as adequate salt. Moreover, as per UNICEF consultant report explicitly that consumption of edible salt with $0 \mathrm{ppm}$ iodine was $34.5 \%$ in Tamil Nadu State as per NFHS III survey 200506. [28] Whereas $88 \%$ of people took iodized salt in their daily diet. [29] In the UNICEF report as per year 2006 - 07 had stated that $65.2 \%$ and $58.2 \%$ in upper and lower Egypt respectively; but in year $2014-$ 15 it was shown high $72.6 \%$ and $74.6 \%$ in upper and lower Egypt respectively. [30] So, the iodine content is varying from region to region in India. [31]

In a study, the level of iodine content was in packaged crushed, crystal salt, and loose crystal salts $31.4 \%, 58.6 \%$, and $9.9 \%$ respectively. [23] In our study, out of 1233 households, $693(56.2 \%)$ households were bought packed and loose crystalline salts. In that, $66(9.5 \%)$ were packed and loose crystalline salts. Out of 66 salts, $10(2.2 \%)$ were packed crystalline salts bought from the local grocery store, in that 2 $(0.2 \%)$ loose crystalline salt, $56(84.8 \%)$ were loose crystalline and it was provided by a salt ambulant vendor. The adequate iodine content in packed powered salt $29.4 \%$, and total packed, loose crystalline salt was $23.2 \%$. To eliminate the iodine deficiency and to estimate the iodine nutrition among countries by conducting nationwide surveys. [20] The main limitations of the study were those who were available in the household's maximum women. Some households were closed due to working days.

\section{Conclusion:}

From our present study findings, we have concluded that the majority of study population used iodized salt in their regular food. But, very less adequately iodized salts were available in the study area. Nevertheless, the majority of households didn't know about the benefits about usage of iodized diet salt. Health education is needed in 
selling adequate iodized salt in nearby grocery stores/shops/malls/supermarkets and to improve knowledge about iodized salt among shopkeepers and local salt vendors. Iodized salt provided through the public delivery system to study rural areas. This will be done through health education in schools, colleges and community level, by communication and information (ECI) would be conducted by Non-Governmental organizations, Government organizations and other in and around medical colleges.

Recommendations: Health education related to usage of iodized salt, how to store the iodized salt in the household level, how to identify the iodized salt in the grocery shops. In school level also the iodine related health study is needed in and around study areas.

Acknowledgement: Authors are very much thankful to the DirectorPrincipal, Head of the Department and those who have involved in the study including teaching faculties, ANMs, staff nurses, Undergraduate interns those who were posted in the rural health center, Post Graduates and other non-teaching staffs.

Authors' Contributions: SV, MN: Study conception and design; SV: data collection, draft manuscript preparation. All authors reviewed the results and approved the final version of the manuscript.

SV - Senthilvel Vasudevan and MN - Murugan Natesan

Conflict of interest: The authors are not having any type of conflict of interest in the study.

Source of funding: We didn't get any kind of funding from the parent institution or any other financial institutions or organizations. We didn't give any incentives to the study participants.

\section{References:}

1. Ahad F and Ganie SA. Iodine, Iodine metabolism and Iodine deficiency disorders revisited. Indian Journal of Endocrinology and Metabolism 2010;14(1):13-17. PMID: 21448409.

2. Andersson M, Karumbunathan V, Zimmermann MB. Global iodine status in 2011 and trends over the past decade. J Nutr 2012 Apr;142(4):744-750.

DOI: http://dx.doi.org/10.3945/jn.111.149393

3. Pearce EN, Andersson M, Zimmermann MB. Global iodine nutrition: where do we stand in 2013? Thyroid 2013 May;23(5):523-528. PMID: 23472655 DOI: http://dx.doi.org/10.1089/thy.2013.0128

4. World Health Organization. Bulletin of the World Health Organization: Research - Access to iodized salt in 11 low-and lower-middle-income counties: 2000 and 2010. Available on: https://www.who.int/bulletin/volumes/94/2/15-160036/en/ [Last Accessed on $18^{\text {th }}$ August 2020]

5. Rah JH, Anas AM, Chakrabarty A, Sankar R, Pandav C, Aguayo VM. Towards universal salt iodisation in India: achievements, challenges and future actions. Matern Child Nutr 2015;11(4):483-496. PMID: 23795562 DOI: http://dx.doi.org/10.1111/mcn.12044
6. Yadav K, Chakrabarty A, Rah JH, Kumar R, Aguayo V, Ansari MA et al. The National Coalition for Sustained Optimal Iodine intake (NSOI): a case study of a successful experience from India. Asia Pac J Clin Nutr 2014;23 Suppl 1:S38-S45. PMID: 25384725

7. Kramer M, Kupka R, Subramanian SV, Vollmer S. Association between household unavailability of iodized salt and child growth: evidence from 89 demographic and health surveys. The American Journal of Clinical Nutrition 2016;104(4):1093-1100. DOI: https://doi.org/10.3945/ajen.115.124719

8. Iodine: Fact sheet for Consumers. National Institutes of Health Available on: https://ods.od.nih.gov/factsheets/Iodine-Consumer/ [Last Accessed on: $16^{\text {th }}$ October 2020]

9. Jagriti Chandra. Tamil Nadu ranks lowest in coverage of iodized salt. The Hindu, New Delhi was published on $9^{\text {th }}$ September 2019. Available on: https://ods.od.nih.gov/factsheets/Iodine-Consumer/ [Last Accessed on: 16 ${ }^{\text {th }}$ October 2020]

10. India Iodine Survey Report 2018 - 19. National Report. Nutrition International;2019:22. New Delhi, India. Available on: https://www.ign.org/cm_data/2019-INDIA-IODINE-SURVEY2018-19_FINAL-REPORT.PDF

11. Roy R, Chaturvedi M, Agrawal D and Ali H. Household use of iodized salt in rural area. J Fam Med and Pri Care 2016;5(1):7781. PMID: 27453848

12. World Health Organization. Goitre as a determinant of the prevalence and severity of iodine deficiency disorders in populations. Vitamin and Mineral Nutrition information System: Classification of goitre by palpation 2014:1-6. Available on: https://apps.who.int/iris/bitstream/handle/10665/133706/WHO NMH_NHD_EPG_14.5_eng.pdf;jsessionid=ED159EC9711529F 527C648438D894D5C? sequence $=1$ [Last Accessed on: 22 September 2020]

13. Pandav CS, Arora NK, Krishnan A, Sankar R, Pandav S \& Karmarkar MG. Validation of spot-testing kits to determine iodine content in salt. Bulletin of the World Health Organization 2000;78(8):975-980.

14. MBI KIT: Field Testing Now Easier. MBI KITS international, Chennai, India. Available on: http://www.mbikits.com/the-mbikit/ [Last Accessed on: $22^{\text {nd }}$ September 2020]

15. Nutrition Centre of Expertise: Using Rapid Test Kits to Measure Salt Iodisation at the Household Level - WV Guidance Document. Global Health \& Wash 2011:1-7. Available on: https://www.wvi.org/sites/default/files/Salt-Iodisation-at-

Household-Level.pdf [Last Accessed on: 22 ${ }^{\text {nd }}$ September 2020]

16. Sharma R. Revision of Prasad's social classification and provision of an online tool for real-time updating. South Asian J Cancer 2013;2(3):157. PMID: 24455606

17. Diosady LL, Alberti JO, FitzGerald S and Venkatesh MG. Field tests for iodide in salt. Food and Nutrition Bulletin 1999;20(2):215-220. DOI: https://doi.org/10.1777/156482659902000206

18. Government of Assam: Health \& Family Welfare. National Iodine Deficiency Disease Control Programme. Available on: https://hfw.assam.gov.in/information-services/detail/nationaliodine-deficiency-disease-control-programme [Last Accessed on: $24^{\text {th }}$ September 2020] 
19. Tariku WB, Mazengia AL. Knowledge and Utilization of Iodized salt and Its Associated Factors at Household Level in Mecha District, Northwest Ethiopia. Journal of Nutrition and Metabolism 2019;1-8. DOI: https://doi.org/10.1155/2019/9763830

20. Iodine Status Worldwide. WHO Global Datebase on Iodine Deficiency. Department of Nutrition for Health and Development, World Health Organization, Geneva 2004; Page No: 45;1-58. Available on: https://apps.who.int/iris/bitstream/handle/10665/43010/9241592001 .pdf [Last Accessed on: $24^{\text {th }}$ October 2020]

21. Kapil U. Current status of salt iodization and level of iodine nutrient in India. African Journal of Pharmacy and Pharmacology 2008;2(3):066-076.

22. Deepika PS, Rao BT, Vamsi A, Valleswary K, Sekhar MC. A cross sectional study on proper use of iodized salt in communities of rural areas and its relevant factors in Prakasam district, Andhra Pradesh, India. International Journal of Community Medicine and Public Health 2019;6(3):1083-1090. DOI: http://dx.doi.org/10.18203/2394-6040.ijcmph20190590

23. Summary Report Iodized Salt Coverage Study 2010: Conducted Across Eight States in India. Micronutrient Initiative, ICCIDD, Nielsen, Government of India 2011:1-32. Available on: https://www.nutritionintl.org/content/user_files/2011/06/india-saltcoverage-report-2010.pdf [Last Accessed on: $24^{\text {th }}$ October 2020]

24. Kapil U. Successful Efforts Toward Elimination Iodine Deficiency Disorders in India. Indian J Community Med 2010;35(4):455-468. PMID: 21278862

25. Double Fortified Salt. Food Fortification Resource Centre: Food Safety and Standards Authority of India. Available on: https://ffrc.fssai.gov.in/commodity?commodity=double-fortifiedsalt\#: :text=Double\%20Fortified\%20Salt\%20(DFS)\%20is,human \%20beings\%20through\%20their\%20diet.\&text=Dual\%20fortificati on\%20of\%20salt\%20with,combat \%20iodine\%20and\%20iron\%20d eficiencies [Last Accessed on $22^{\text {nd }}$ October 2020]

26. Pandav CS, Yadav K, Srivastava R, Panday R, and Karmarkar MG. Iodine deficiency disorders (IDD) control in India. Indian J Med Res 2013;138(3):418-433. PMID: 24135192

27. Sankar R, Moorthy D, Pandav CS, Tiwari JS, Karmarkar MG. Tracking progress towards sustainable elimination of iodine deficiency disorders in Bihar. Indian J Pediatr 2006:73(9):799-802. PMID: 17006038

28. Vir SC. Universal Salt Iodisation (USI) in India - Current Situation and Proposed Actions. 1-79. Available on: https://files.givewell.org/files/DWDA\%202009/GAIN/Universal\%2 0Salt\%20Iodisation\%20(USI)\%20in\%20India\%20\% 2\%80\%93\%2 0Current\%20Situation\%20and\%20Proposed\%20Actions.pdf [Last Accessed on: $1^{\text {st }}$ November 2020]

29. Iodine: United Nations International Children's Emergency Fund Data. UNICEF 2019. Available on: https://data.unicef.org/topic/nutrition/iodine/ [Last Accessed on: $24^{\text {th }}$ October 2020]

Publish your research articles with International Journal of Medical Sciences and Nursing Research Website: http://ijmsnr.com/
30. National Survey of Iodine Status and Household Iodised Salt Use among Primary School Children and Pregnant Women. UNICEF and Global Alliance for Improved Nutrition (GAIN) Report 2014-2015; Page No:45:1-146. Available on: https://www.unicef.org/eg iodine full report final oct $M$ G_v3.pdf

31. Singh MB, Sharma SK, Nair S, Pandey RM, Kapil U, Singh C. Status of Iodine content of salt in four regions of India. Indian J Pediatr 2011;78(6):684-687. PMID: 21193974 